\title{
Solvent Extraction of Gd from Chloride Solution with PC88A
}

\author{
Man-Seung Lee ${ }^{1, *}$, Gwang-Seop Lee ${ }^{1}$, Jin-Young Lee ${ }^{2}$, Sung-Don Kim², \\ Jae-Woo Ahn ${ }^{3}$ and Joon-Soo Kim² \\ ${ }^{1}$ Department of Advanced Materials Science \& Engineering, Mokpo National University, Chonnam 534-729, Korea \\ ${ }^{2}$ Division of Minerals Utilization and Materials, Korea Institute of Geoscience and Mineral Resources, Taejon 305-350, Korea \\ ${ }^{3}$ Department of Advanced Materials Science \& Engineering, Daejin University, Kyonggi 487-711, Korea
}

Solvent extraction experiments of Gd from chloride solution with PC88A were conducted at different extraction conditions. Solvent extraction reaction was identified from the experimental results using a graphical method, and the corresponding effective equilibrium constant was determined by analyzing the ionic equlibria in a $\mathrm{GdCl}_{3}$ solution. In the experimental ranges investigated in this study, i.e., $\left[\mathrm{GdCl}_{3}\right] \leq 0.3 \mathrm{kmol} / \mathrm{m}^{3},[\mathrm{PC} 88 \mathrm{~A}]_{\text {org }} \leq 3.0 \mathrm{kmol} / \mathrm{m}^{3}$ and initial $\mathrm{pH} \leq 2.3$, solvent extraction reaction of Gd with PC88A and the corresponding effective equilibrium constant were obtained as follows $\mathrm{Gd}^{3+}+2 \mathrm{H}_{2} \mathrm{~A}_{2, \text { org }}=\mathrm{GdA}_{3} \mathrm{HA}_{\text {org }}+3 \mathrm{H}^{+}, K_{\text {ex,eff }}=2.8 \times 10^{-1}$.

(Received September 6, 2004; Accepted December 1, 2004)

Keywords: $\mathrm{GdCl}_{3}, \mathrm{PC} 88 \mathrm{~A}$, solvent extraction

\section{Introduction}

Rare earth elements have superior characteristics such as in magnetic, optical and catalytic properties. Gadolinium is one of rare earth elements and is the raw material for GGG(Ga-Gd-Garnets). Owing to the similarity in the chemical nature of the rare earth elements, the mutual separation and purification of them is difficult. Solvent extraction has been extensively studied to separate the rare earth elements on an industrial scale. Acidic organophosphrous extractants, such as D2EHPA and PC88A, are widely used in the separation of rare earth elements. ${ }^{1,2)}$ Of these two extractants, PC88A is known to have high loading capacity and to yield high separation factor. ${ }^{3)}$

It is necessary to know the solvent extraction behavior of each rare earth element. Few studies, however, have been performed on the solvent extraction of Gd with PC88A. In this study, we conducted solvent extraction experiments of Gd from chloride solution with PC88A at various conditions. From the experimental results, the solvent extraction reaction was identified using a graphical method. On the assumption that the activity coefficients of chemical species in the aqueous phase are constant, and the species in the organic behave ideally, the effective equilibrium constant for the solvent extraction was obtained by analyzing the ionic equilibria.

\section{Experimental}

A $\mathrm{GdCl}_{3}$ solution was prepared by dissolving $\mathrm{Gd}_{2} \mathrm{O}_{3}$ (99.9\%, Strem Chemicals) in excess $\mathrm{HCl}$ solution. The excess $\mathrm{HCl}$ was evaporated using hot plate. A small amount of $\mathrm{HCl}$ solution was added to the stock solution to adjust the acidity of the solution. The organic phase was prepared by diluting PC88A with kerosene and all chemicals were of reagent grade.

The phase ratio was kept at unity in all solvent extraction

*Corresponding author, E-mail: mslee@mokpo.ac.kr experiments. Equal volumes of aqueous and organic solutions were placed in a $100 \mathrm{~mL}$ separatory funnel and shaken for an hour at ambient temperature with a wrist action shaker. The aqueous phase was separated after settling the mixture for $24 \mathrm{~h}$. Solution $\mathrm{pH}$ was measured with a $\mathrm{pH}$ meter (Fisher Accumet $\mathrm{pH}$ model 620). The concentration of $\mathrm{Gd}$ in the aqueous phase was measured by ICP-AES (Spectrflame, EOP), while that of Gd in the organic phase was calculated by using mass balance.

\section{Results and Discussion}

\subsection{Extraction reaction of Gd with PC88A}

Figure 1 shows the effect of equilibrium $\mathrm{pH}$ on the distribution coefficient of $0.1 \mathrm{kmol} / \mathrm{m}^{3} \mathrm{Gd}$ at different

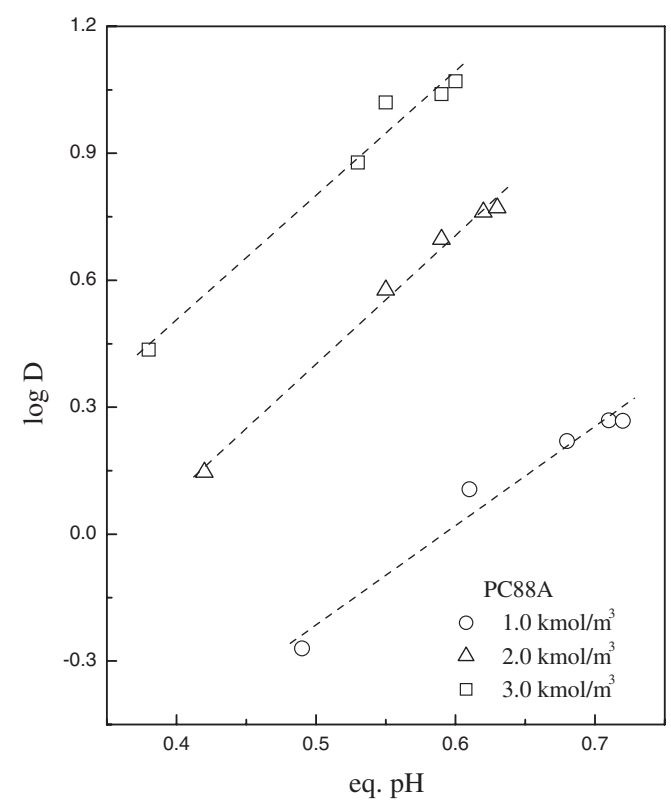

Fig. 1 Effect of equilibrium $\mathrm{pH}$ on the distribution coefficient of $\mathrm{Gd}$ at different PC88A concentrations. $\left(\left[\mathrm{GdCl}_{3}\right]^{\mathrm{I}}=0.1 \mathrm{kmol} / \mathrm{m}^{3}\right)$ 


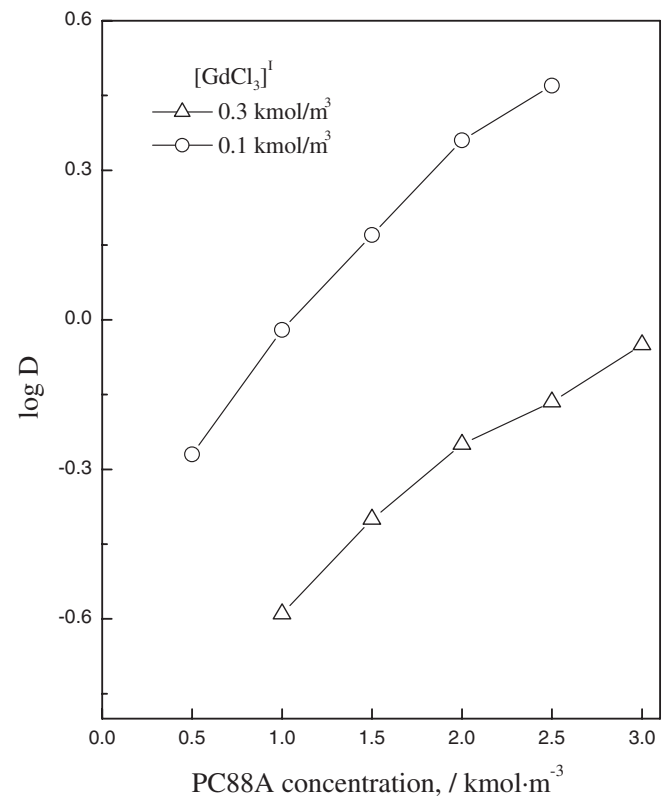

Fig. 2 Effect of PC88A concentration on the distribution coefficient of Gd at different $\mathrm{GdCl}_{3}$ concentrations.

PC88A concentrations. In this figure, superscript I represents the initial concentration of $\mathrm{GdCl}_{3}$. Distribution coefficients of Gd increased linearly with equilibrium $\mathrm{pH}$ and the slope of the plot was 3 . The value of the slope indicated that three moles of hydrogen ion in PC88A were exchanged for one mole of Gd extracted into the organic phase. Figure 2 shows the variation in the distribution coefficients of $\mathrm{Gd}$ with PC88A concentration, when the initial concentration of $\mathrm{Gd}$ was 0.1 and $0.3 \mathrm{kmol} / \mathrm{m}^{3}$, respectively. Distribution coefficients of Gd increased rapidly with PC88A concentration.

Solvent extraction reaction of $\mathrm{Gd}$ from chloride solution with PC88A may be represented by

$$
\mathrm{Gd}^{3+}+\frac{(3+x)}{2} \mathrm{H}_{2} \mathrm{~A}_{2, \text { org }}=\mathrm{GdA}_{3} x \mathrm{HA}_{\text {org }}+3 \mathrm{H}^{+}
$$

where $\mathrm{H}_{2} \mathrm{~A}_{2}$ represents a dimeric PC88A and subscript org the organic phase.

Inserting the definition of distribution coefficient $D$ into the equilibrium constant for the above reaction $K_{\mathrm{ex}}$, and taking logarithm on both sides resulted in

$$
\log D-3 \mathrm{pH} \cong \frac{(3+x)}{2} \log \left[\mathrm{H}_{2} \mathrm{~A}_{2}\right]_{\text {org }}+\log K_{\mathrm{ex}}
$$

where $\left[\mathrm{H}_{2} \mathrm{~A}_{2}\right]$ represents the equilibrium concentration of PC88A and can be obtained by the following equation.

$$
\left[\mathrm{H}_{2} \mathrm{~A}_{2}\right]_{\text {org }}=\left[\mathrm{H}_{2} \mathrm{~A}_{2}\right]_{\mathrm{org}}^{\mathrm{I}}-\frac{(3+x)}{2}\left[\mathrm{GdA}_{3} x \mathrm{HA}\right]_{\text {org }}
$$

In the experimental ranges conducted in this study, solvent extraction reaction of Gd with PC88A was identified using a graphical method. Equation (2) reveals that the plot of $\log D-3 \mathrm{pH}$ against $\log \left[\mathrm{H}_{2} \mathrm{~A}_{2}\right]_{\text {org }}$ should give a straight line with a slope of $(3+x) / 2$. First, the equilibrium concentration of PC88A was calculated with eq. (3) by varying the value of $x$ from zero to 3 . For an assigned value of $x$, we investigated the agreement between the slope of the plot and the value of
Table 1 Complex formation reactions and corresponding equilibrium constant at $298 \mathrm{~K}$.

\begin{tabular}{lcc}
\hline \multicolumn{1}{c}{ Reaction } & Equilibrium constant & Ionic strength \\
\hline $\mathrm{H}^{+}+\mathrm{OH}^{-}=\mathrm{H}_{2} \mathrm{O}$ & $K_{1}=1.00 \times 10^{14}$ & 0 \\
$\mathrm{Gd}^{3+}+\mathrm{Cl}^{-}=\mathrm{GdCl}^{2+}$ & $K_{2}=6.92 \times 10^{-1}$ & $1.0 \mathrm{kmol} / \mathrm{m}^{3}$ \\
$\mathrm{Gd}^{3+}+\mathrm{OH}^{-}=\mathrm{GdOH}^{2+}$ & $K_{3}=1.48 \times 10^{6}$ & 0 \\
$\mathrm{Gd}^{3+}+2 \mathrm{OH}^{-}=\mathrm{Gd}(\mathrm{OH})_{2}{ }^{+}$ & $K_{4}=3.72 \times 10^{12}$ & 0 \\
\hline
\end{tabular}

$(3+x) / 2$. The plot in Fig. 3 yielded a straight line with a slope of 2.12 only when the value of $x$ was one. From this result, it might be inferred that eq. (4) represents the solvent extraction reaction of $\mathrm{Gd}$ from chloride solution with PC88A in the experimental ranges investigated in this study, i.e., $\left[\mathrm{GdCl}_{3}\right] \leq 0.3 \mathrm{kmol} / \mathrm{m}^{3},[\mathrm{PC} 88 \mathrm{~A}]_{\text {org }} \leq 3.0 \mathrm{kmol} / \mathrm{m}^{3}$ and initial $\mathrm{pH} \leq 2.3$.

$$
\mathrm{Gd}^{3+}+2 \mathrm{H}_{2} \mathrm{~A}_{2, \text { org }}=\mathrm{GdA}_{3} \mathrm{HA}_{\text {org }}+3 \mathrm{H}^{+}
$$

\subsection{Prediction of the distribution coefficients of Gd}

In order to predict the distribution coefficients of $\mathrm{Gd}$ from the initial extraction conditions, equilibrium concentrations of all the chemical species in both phases after extraction should be known. Table 1 represents the complex formation reactions considered in this study and the corresponding equilibrium constant at $298 \mathrm{~K}^{4)}$ In Table 1 , the equilibrium constant other than zero ionic strength was reported for the formation of $\mathrm{GdCl}^{2+}$. This value of the equilibrium constant for the formation of $\mathrm{GdCl}^{2+}$ was used without correction in this study. When we consider the complex formation reactions and solvent extraction reaction, the number of chemical species in both phases after extraction would be nine $\left(\mathrm{Gd}^{3+}, \mathrm{GdCl}^{2+}, \mathrm{GdOH}^{2+}, \mathrm{Gd}(\mathrm{OH})_{2}{ }^{+}, \mathrm{H}^{+}, \mathrm{Cl}^{-}, \mathrm{OH}^{-}\right.$, $\mathrm{GdA}_{3} \mathrm{HA}$ and $\mathrm{H}_{2} \mathrm{~A}_{2}$ ). When the volume ratio of aqueous to organic is unity, the mass balance equations and charge balance equation are represented by

$$
\begin{aligned}
& {[\mathrm{Gd}]^{\mathrm{I}}=} {\left[\mathrm{Gd}^{3+}\right]+\left[\mathrm{GdCl}^{2+}\right]+\left[\mathrm{GdOH}^{2+}\right] } \\
&+\left[\mathrm{Gd}(\mathrm{OH})_{2}{ }^{+}\right]+\left[\mathrm{GdA}_{3} \mathrm{HA}\right]_{\mathrm{org}} \\
& {[\mathrm{Cl}]^{\mathrm{I}}=3\left[\mathrm{GdCl}_{3}\right]^{\mathrm{I}}+[\mathrm{HCl}]^{\mathrm{I}}=\left[\mathrm{Cl}^{-}\right]+\left[\mathrm{GdCl}^{2+}\right] } \\
& {\left[\mathrm{H}_{2} \mathrm{~A}_{2}\right]_{\mathrm{org}}^{\mathrm{I}}=\left[\mathrm{H}_{2} \mathrm{~A}_{2}\right]_{\mathrm{org}}+2\left[\mathrm{GdA}_{3} \mathrm{HA}\right]_{\mathrm{org}} } \\
& {\left[\mathrm{H}^{+}\right]+3\left[\mathrm{Gd}^{3+}\right]+2\left[\mathrm{GdCl}^{2+}\right]+2\left[\mathrm{GdOH}^{2+}\right] } \\
&+\left[\mathrm{Gd}(\mathrm{OH})_{2}{ }^{+}\right]=\left[\mathrm{Cl}^{-}\right]+\left[\mathrm{OH}^{-}\right]
\end{aligned}
$$

In making use of a mass balance equation for chloride, the initial concentration of $\mathrm{HCl}$ should be known. Since the excess $\mathrm{HCl}$ was evaporated in preparing a $\mathrm{GdCl}_{3}$ stock solution, the exact concentration of $\mathrm{HCl}$ was not known. Therefore, we calculated the total concentration of chloride from the initial concentration of $\mathrm{GdCl}_{3}$ and the value of initial $\mathrm{pH}$. When the complex formation reactions shown in Table 1 are considered, the number of the chemical species in a $\mathrm{GdCl}_{3}$ solution would be seven $\left(\mathrm{Gd}^{3+}, \mathrm{GdCl}^{2+}, \mathrm{GdOH}^{2+}\right.$, $\mathrm{Gd}(\mathrm{OH})_{2}{ }^{+}, \mathrm{H}^{+}, \mathrm{Cl}^{-}$and $\left.\mathrm{OH}^{-}\right)$. Seven independent equations are needed to calculate the equilibrium concentration of these chemical species from the composition of a $\mathrm{GdCl}_{3}$ solution. These seven independent equations were obtained from the four complex formation reactions shown in Table 1, a mass 
Table 2 Measured and calculated data for the extraction of Gd with PC88A.

\begin{tabular}{|c|c|c|c|c|c|c|c|c|}
\hline \multirow[b]{2}{*}{$\mathrm{N}$} & \multicolumn{3}{|c|}{ Initial condition } & \multicolumn{2}{|c|}{ Measured values } & \multicolumn{3}{|c|}{ Calculated values } \\
\hline & {$[\mathrm{Gd}]^{\mathrm{I}}$} & {$[\mathrm{PC} 88 \mathrm{~A}]_{\text {org }}^{\mathrm{I}}$} & $\mathrm{pH}^{\mathrm{I}}$ & $\log D$ & $\mathrm{pH}_{\mathrm{eq}}$ & {$[\mathrm{HCl}]^{\mathrm{I}}$} & $\mathrm{pH}_{\mathrm{eq}}$ & $\log D$ \\
\hline 1 & 0.106 & 0.2 & 0.82 & -1.17 & 0.74 & 0.215 & 0.76 & -0.95 \\
\hline 2 & 0.106 & 0.4 & 0.82 & -1.13 & 0.67 & 0.215 & 0.70 & -0.55 \\
\hline 3 & 0.106 & 0.6 & 0.82 & -0.37 & 0.61 & 0.215 & 0.65 & -0.33 \\
\hline 4 & 0.106 & 0.8 & 0.82 & -0.27 & 0.55 & 0.215 & 0.61 & -0.17 \\
\hline 6 & 0.106 & 1.5 & 0.82 & 0.11 & 0.43 & 0.215 & 0.52 & 0.20 \\
\hline 7 & 0.30 & 0.5 & 0.57 & -1.30 & 0.50 & 0.349 & 0.50 & -0.94 \\
\hline 8 & 0.30 & 1.0 & 0.57 & -0.60 & 0.41 & 0.349 & 0.43 & -0.59 \\
\hline 9 & 0.30 & 1.5 & 0.57 & -0.41 & 0.34 & 0.349 & 0.37 & -0.39 \\
\hline 10 & 0.30 & 2.0 & 0.57 & -0.25 & 0.28 & 0.349 & 0.33 & -0.25 \\
\hline 11 & 0.30 & 2.5 & 0.57 & -0.17 & 0.23 & 0.349 & 0.29 & -0.14 \\
\hline 13 & 0.10 & 0.5 & 0.65 & -0.29 & 0.57 & 0.312 & 0.58 & -0.61 \\
\hline 14 & 0.10 & 1.0 & 0.65 & -0.02 & 0.50 & 0.312 & 0.51 & -0.20 \\
\hline 15 & 0.10 & 1.5 & 0.65 & 0.17 & 0.45 & 0.312 & 0.46 & 0.05 \\
\hline 16 & 0.10 & 2.0 & 0.65 & 0.36 & 0.42 & 0.312 & 0.42 & 0.22 \\
\hline 17 & 0.10 & 2.5 & 0.65 & 0.47 & 0.40 & 0.312 & 0.40 & 0.38 \\
\hline 18 & 0.10 & 1.0 & 0.59 & -0.27 & 0.49 & 0.356 & 0.47 & -0.27 \\
\hline 19 & 0.10 & 1.0 & 1.00 & 0.11 & 0.61 & 0.144 & 0.63 & 0.13 \\
\hline 20 & 0.10 & 1.0 & 1.28 & 0.22 & 0.68 & 0.076 & 0.69 & 0.27 \\
\hline 21 & 0.10 & 1.0 & 1.83 & 0.27 & 0.71 & 0.022 & 0.74 & 0.42 \\
\hline 22 & 0.10 & 1.0 & 2.31 & 0.28 & 0.72 & 0.007 & 0.75 & 0.46 \\
\hline 23 & 0.10 & 2.0 & 0.59 & 0.15 & 0.42 & 0.356 & 0.40 & 0.15 \\
\hline 24 & 0.10 & 2.0 & 1.00 & 0.58 & 0.55 & 0.144 & 0.54 & 0.56 \\
\hline 25 & 0.10 & 2.0 & 1.28 & 0.70 & 0.59 & 0.076 & 0.60 & 0.73 \\
\hline 28 & 0.10 & 3.0 & 0.59 & 0.44 & 0.38 & 0.356 & 0.36 & 0.43 \\
\hline 29 & 0.10 & 3.0 & 1.00 & 0.88 & 0.53 & 0.144 & 0.50 & 0.86 \\
\hline 30 & 0.10 & 3.0 & 1.28 & 1.03 & 0.55 & 0.076 & 0.57 & 1.04 \\
\hline 31 & 0.10 & 3.0 & 1.83 & 1.05 & 0.59 & 0.022 & 0.63 & 1.25 \\
\hline 32 & 0.10 & 3.0 & 2.31 & 1.07 & 0.60 & 0.007 & 0.65 & 1.33 \\
\hline
\end{tabular}

Unit of concentration: molarity

balance equation for $\mathrm{Gd}$, a charge balance equation and the value of initial $\mathrm{pH}$. Once the concentration of the hydrogen ion was obtained from the initial $\mathrm{pH}$, the concentration of the chloride ion can be calculated using the charge balance, and that of $\mathrm{Gd}^{3+}$ from the mass balance for $\mathrm{Gd}$. The concentration of $\mathrm{GdCl}^{2+}$ was calculated using complex formation reaction, and the total concentration of chloride was equal to the sum of the concentrations of $\mathrm{Cl}^{-}$and $\mathrm{GdCl}^{2+}$.

There would be 9 chemical species in both phases after extraction, i.e., $\mathrm{Gd}^{3+}, \mathrm{GdCl}^{2+}, \mathrm{GdOH}^{2+}, \mathrm{Gd}(\mathrm{OH})_{2}{ }^{+}, \mathrm{H}^{+}$, $\mathrm{Cl}^{-}, \mathrm{OH}^{-}, \mathrm{GdA}_{3} \mathrm{HA}$ and $\mathrm{H}_{2} \mathrm{~A}_{2}$. Nine independent equations are necessary in predicting the distribution coefficients of $\mathrm{Gd}$ from the initial extraction conditions. These independent equations are obtained from the four complex formation reactions, 3 mass balance equations ( $\mathrm{Gd}, \mathrm{Cl}$ and $\mathrm{PC} 88 \mathrm{~A}$ ), a charge balance equation and solvent extraction reaction. These equations were solved using Newton-Raphson method. Since the concentration range of $\mathrm{GdCl}_{3}$ is narrow in this study, the activity coefficients of chemical species in the aqueous phase are assumed to be constant. Moreover, ideal behavior was assumed for the chemical species in the organic phase. With this assumption, the effective equilibrium constant for the solvent extraction of $\mathrm{Gd}$ with PC88A is represented as

$$
K_{\text {ex }, \text { eff }}=K_{\text {ex }} \times \frac{\gamma_{\mathrm{Gd}^{3+}}}{\left(\gamma_{\mathrm{H}^{+}}\right)^{3}}=\frac{\left[\mathrm{GdA}_{3} \mathrm{HA}\right]_{\mathrm{org}}\left[\mathrm{H}^{+}\right]^{3}}{\left[\mathrm{Gd}^{3+}\right]\left[\mathrm{H}_{2} \mathrm{~A}_{2}\right]_{\mathrm{org}}^{2}}
$$

In order to estimate the above effective equilibrium constant, an evaluation function was defined as follows:

$$
\text { Err }=\frac{1}{N} \sum\left(\log D_{\text {calc }}-\log D_{\text {meas }}\right)^{2}
$$

where $N$ denotes the number of experimental data and $D_{\text {calc }}$ and $D_{\text {meas }}$ represent the distribution coefficient of $\mathrm{Gd}$ calculated in this study and measured, respectively. The effective equilibrium constant for the solvent extraction of Gd with PC88A was estimated to be $2.8 \times 10^{-1}$ by minimizing the Err function. Table 2 shows the extraction conditions and the experimental data. The calculated values, such as $\mathrm{HCl}$ concentration, equilibrium $\mathrm{pH}$ and distribution coefficient of Gd were also shown in Table 2. Figure 4 shows the measured distribution coefficients of $\mathrm{Gd}$ and the 


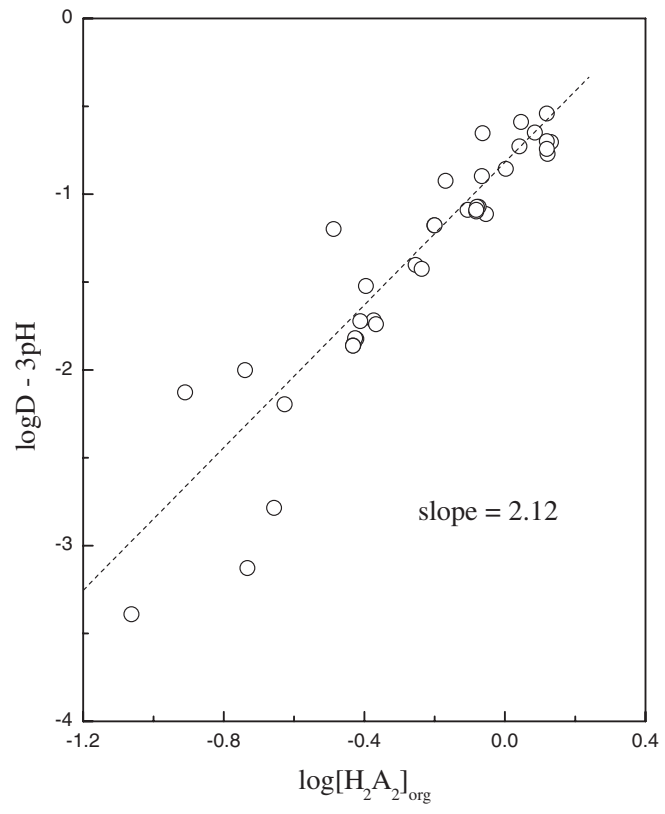

Fig. 3 Equilibrium plot of $\log D-3 \mathrm{pH}$ against the $\log$ arithm of equilibrium concentration of PC88A.

calculated values in this study. Standard deviation between the two values was 0.03 , indicating good agreement between the two distribution coefficients of Gd.

\section{Conclusions}

Solvent extraction reaction of Gd from chloride solution with PC88A was identified from the experimental data by using a graphical method. The corresponding effective equilibrium constant for the solvent extraction was estimated by analyzing the ionic equilibria. The ionic equilibria for a $\mathrm{GdCl}_{3}$ solution was analyzed by considering the complex formation reactions as well as the mass and charge balance equations. In the experimental ranges investigated in this

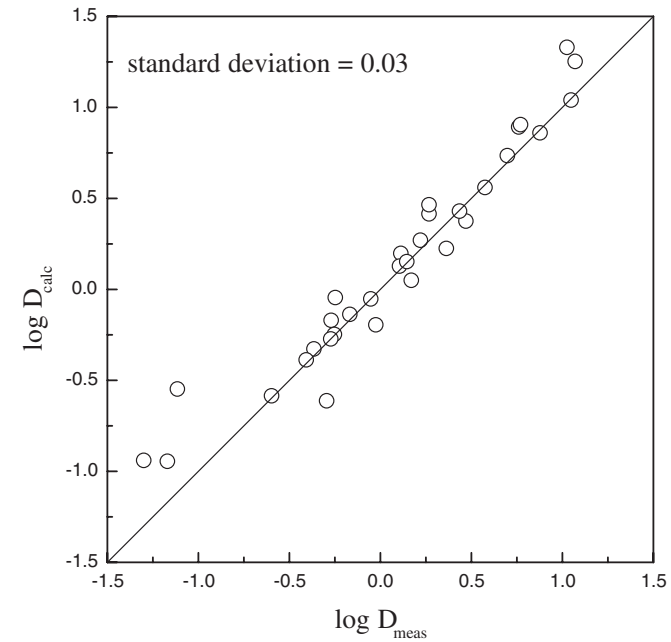

Fig. 4 Comparison of Gd distribution coefficients between measured and calculated in this study.

study, i.e., $\left[\mathrm{GdCl}_{3}\right] \leq 0.3 \mathrm{kmol} / \mathrm{m}^{3},[\mathrm{PC} 88 \mathrm{~A}]_{\mathrm{org}} \leq 3.0 \mathrm{kmol} /$ $\mathrm{m}^{3}$ and initial $\mathrm{pH} \leq 2.3$, the following solvent extraction reaction of Gd with $\mathrm{PC} 88 \mathrm{~A}$ and the corresponding effective equilibrium constant was obtained.

$$
\begin{aligned}
\mathrm{Gd}^{3+}+2 \mathrm{H}_{2} \mathrm{~A}_{2, \text { org }} & =\mathrm{GdA}_{3} \mathrm{HA}_{\text {org }}+3 \mathrm{H}^{+}, \\
K_{\text {ex }, \text { eff }} & =2.8 \times 10^{-1}
\end{aligned}
$$

\section{REFERENCES}

1) S. N. Bhattacharyya and K. M. Ganguly: Hydrometallurgy 32 (1993) 201-208.

2) A. A. Abdeltawab, S. Nii, F. Kawaizumi and K. Takahashi: Separation and Purification Technology 26 (2002) 265-272.

3) N. V. Thakur, D. V. Jayawant, N. S. Iyer and K. S. Koppiker: Hydrometallurgy 34 (1993) 99-108.

4) L. D. Pettit and K. J. Powell: Stability Constant Database Release 5, (Academic Software, 2001). 